\title{
Main barriers on glucometer utilization during physician's appointment of insulin users T2D patients
}

\author{
Cristal Peters Cabral, Erika Bezerra Parente, Paula Vieira Freire*, Andre Carvalho Yamaya, Caroline Schnoll, \\ Vivian Roberta Ferreira Simões, Alessandra Muto, João Eduardo Nunes Salles
}

From 20th Brazilian Diabetes Society Congress

Porto Alegre, Brazil. 11-18 November 2015

\section{Background}

Self-monitoring blood glucose (SMBG) is an important tool for type 2 diabetes treatment, especially for insulin users. However, several patients that receive this device from government do not make the proper use of it.

\section{Objective}

Investigate the main barriers for glucometer utilization to evaluate glycemic control of insulin users T2D patients, during physician's appointment.

\section{Method}

Glycemic data was obtained from patient's glucometers by using Accu Chek 360 software for downloading. We used data of all insulin users T2D patients that came for physician's appointment at the diabetes unit in a public hospital, in the city of Sao Paulo, from March to June 2015. A survey regarding the glucometer usage was applied.

\section{Results}

From a total of 417 patients, 95 were eligible to this analisys. It was not possible to use glucometer information in $31.6 \%$ of 95 patients because the reasons on figure 1 . It was suitable to collect data from $68.4 \%$ of 95 patients, nevertheless, $43.1 \%$ of these performed less than 90 blood glucose tests (less than once a day) and causes are shown in figure 2 .

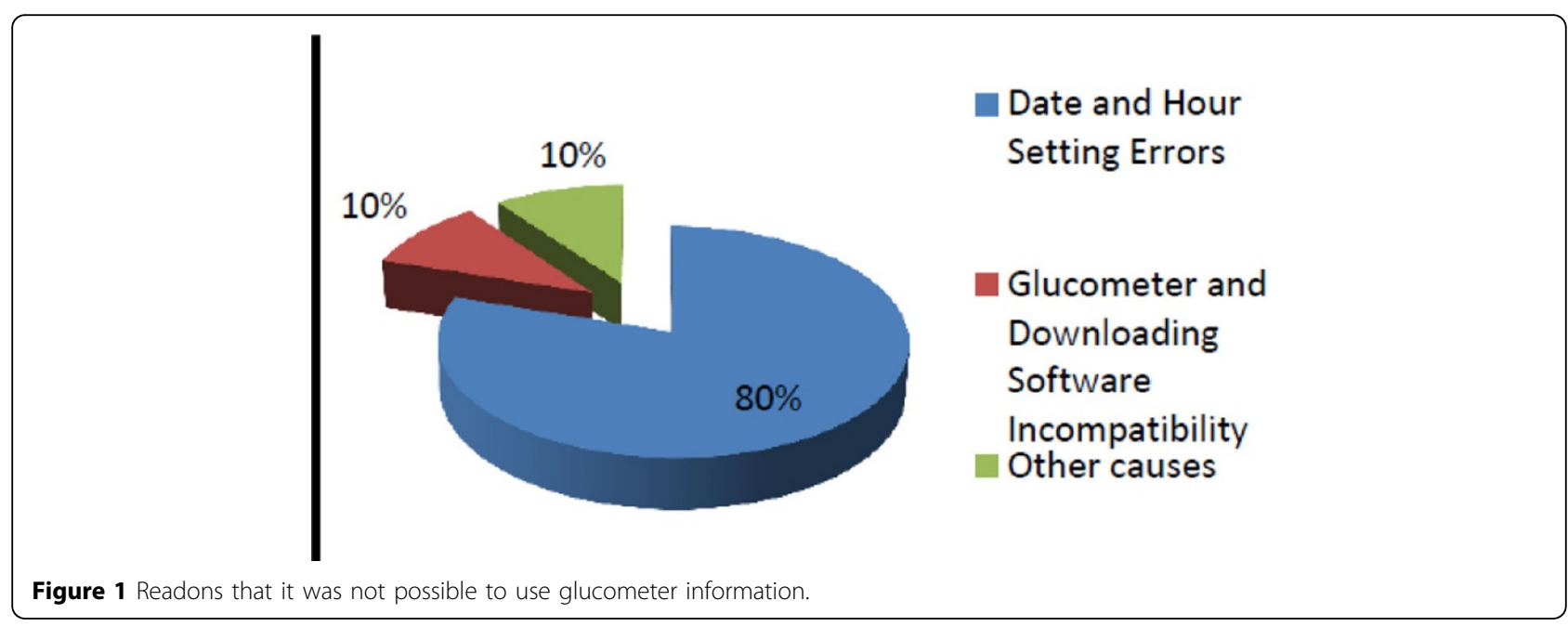

\footnotetext{
* Correspondence: paulavf@hotmail.com

Santa Casa de Misericordia de São Paulo, São Paulo, Brazil
} 


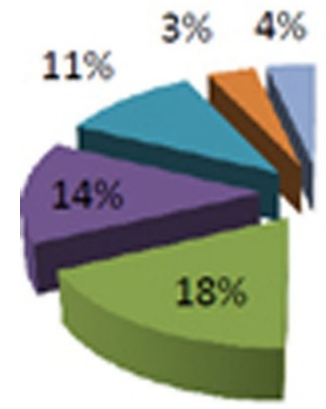

FIGURE 02
Lack of Motivation

to Treat Diabetes

Painful SMBG

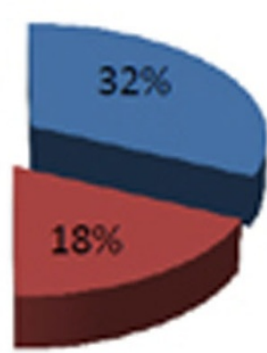

Lack of Finger

Strips

Device Problems

Device Change

Did Not Answer

the Survey

Need of Someone

Else to do SMBG

Figure 2 Reasons that less than 90 blood glucose tests were performed.

\section{Conclusion}

Insulin users T2D patients receive glucometer and supplies from government for free, however the device information was useful only in $56.9 \%$ of all cases. The main reason was lack of information how to use the device and the second was lack of motivation to keep diabetes treatment. Our results showed that we need more education programs for our patients becouse giving glucometer without education will not help diabetes treatment.

Published: 11 November 2015

doi:10.1186/1758-5996-7-S1-A201

Cite this article as: Cabral et al:: Main barriers on glucometer utilization during physician's appointment of insulin users T2D patients.

Diabetology \& Metabolic Syndrome 2015 7(Suppl 1):A201.
Submit your next manuscript to BioMed Central and take full advantage of:

- Convenient online submission

- Thorough peer review

- No space constraints or color figure charges

- Immediate publication on acceptance

- Inclusion in PubMed, CAS, Scopus and Google Scholar

- Research which is freely available for redistribution 